\title{
Synthesis and antiplasmodial evaluation of novel mefloquine-based fumardiamides
}

\author{
MAJA BEUS1,a \\ DIANA FONTINHA 2,a \\ JANA HELD ${ }^{3}$ \\ ZRINKA RAJIĆ ${ }^{1}$ \\ MIGUEL PRUDÊNCIO ${ }^{2}$ \\ BRANKA ZORC ${ }^{1, *}$ \\ ${ }^{1}$ University of Zagreb \\ Faculty of Pharmacy and Biochemistry \\ Department of Medicinal Chemistry \\ 10000 Zagreb, Croatia \\ ${ }^{2}$ Instituto de Medicina Molecular \\ Faculdade de Medicina, Universidade \\ de Lisboa, 1649-028 Lisboa, Portugal \\ ${ }^{3}$ University of Tübingen \\ Institute of Tropical Medicine \\ 72074 Tübingen, Germany
}

Accepted February 14, 2019

Published online February 28, 2019

\begin{abstract}
The paper is focused on the synthesis and screening of the antiplasmodial activity of novel fumardiamides 5-10 with the mefloquine pharmacophore and a Michael acceptor motif. Multi-step reactions leading to the title compounds included two amide bond formations. The first amide bond was achieved by the reaction of (E)-ethyl 4-chloro-4-oxobut2-enoate (1) and $N^{1}$-(2,8-bis(trifluoromethyl)quinolin-4-yl) butane-1,4-diamine (2). The obtained ester 3 was hydrolyzed and gave acid 4, which then reacted with the selected halogenanilines in the presence of HATU/DIEA and formed products $\mathbf{5 - 1 0}$. Title compounds showed marked, dose dependent activity in vitro against hepatic stages of Plasmodium berghei. $I C_{50}$ values of the most active compounds 5, 7 and 9 bearing 3-fluoro, 3-chloro and 3-trifluoromethyl substituents were $3.04-4.16 \mu \mathrm{mol} \mathrm{L}^{-1}$, respectively. On the other hand, the compounds exerted only weak activity against the erythrocytic stages of two $P$. falciparum strains (Pf3D7 and PfDd2) in vitro, with the exception of compound $5\left(I C_{50}=2.9 \mu \mathrm{mol} \mathrm{L}^{-1}\right)$.
\end{abstract}

Keywords: mefloquine, 2,8-bis(trifluoromethyl)quinoline, fumardiamide, halogenaniline, antiplasmodial activity

Mefloquine (MQ) was launched more than 30 years ago for the prophylaxis and treatment of malaria caused by the multidrug-resistant Plasmodium falciparum. Like other quinoline antimalarials, mefloquine binds to the toxic ferriprotoporphyrin IX and prevents its detoxification (1). In addition, the proposed mefloquine targets include ribosomes, phosphatidylinositol, volume-regulated anion channels and endocytosis. The main disadvantages of mefloquine include its photochemical instability and cardiovascular, hepatic and/ or neuropsychiatric side effects (2). Also, resistance to mefloquine, connected with increased expression of P-glycoprotein PfMDR1 in the digestive vacuole, has developed (3).

To overcome mefloquine drawbacks, numerous mefloquine derivatives have been prepared, not only as novel antimalarials (4), but also as potential anticancer agents $(5,6)$.

\footnotetext{
*Correspondence, bzorc@pharma.hr

a These authors equally contributed to this work.
} 
The activity of mefloquine and mefloquine derivatives against Echinococcus multilocularis has also been reported (7). More recently, mefloquine has received considerable attention as an antimycobacterial agent $(8,9)$. It is active against Mycobacterium avium and M. tuberculosis strains resistant to macrolides, quinolones and rifamycins and shows a synergistic effect with ethambutol and moxifloxacin. Antimycobacterial activity of mefloquine derivatives has also been extensively reported (10-12).

In the last ten years, our research group has designed and prepared more than one hundred primaquine and chloroquine derivatives with urea, bis-urea, acylsemicarbazide, semicarbazide or amide functionalities (13-24). Biological evaluation assays revealed that many of these compounds showed potential as antiproliferative, antioxidative, antitubercular, antiplasmodial or biofilm eradication agents. Further, we have prepared several SAHAquines based on suberoylanilide hydroxamic acid (SAHA) and primaquine motifs, which showed antiplasmodial activity against erythrocytic stages of two P. falciparum strains and against $P$. berghei hepatic stages (22).

In our continued pursuit of novel, biologically active quinoline derivatives, we now present the synthesis and evaluation of the antiplasmodial activity of novel fumardiamides in which one amide bond was achieved with $N^{1}$-(2,8-bis(trifluoromethyl)quinolin4-yl)butane-1,4-diamine and the other amide was achieved with the corresponding halogenaniline. Our compounds can be considered mefloquine derivatives, since they bear the same 2,8-bis(trifluoromethyl)quinoline motif as mefloquine. The carbonyl group conjugated with the carbon-carbon double bond of the central part of molecules also classifies these compounds as Michael acceptors, able to react with biological targets bearing thiol groups. We envisaged that combining the mefloquine pharmacophore with Michael acceptor and halogenaniline moieties could result in the development of novel antimalarial hits.

\section{EXPERIMENTAL}

\section{General}

Melting points were determined on an SMP3 apparatus (Barloworld Scientific, UK) in open capillaries and are uncorrected. A CEM Discover microwave reactor was used for microwave reactions (CEM GmbH, Germany). IR spectra were recorded on a Spectrum One (Perkin-Elmer, UK) and UV-Vis spectra on a Lambda 20 double beam spectrophotometer (Perkin-Elmer, UK). NMR ${ }^{1} \mathrm{H}$ and ${ }^{13} \mathrm{C}$ spectra were recorded at $25{ }^{\circ} \mathrm{C}$ on an NMR Avance 600 spectrometer (Bruker, Germany) at 300.13 or 600.13 and 75.47 or $150.9 \mathrm{MHz}$ for ${ }^{1} \mathrm{H}$ and ${ }^{13} \mathrm{C}$ nuclei, resp. Chemical shifts $(\delta)$ are reported in parts per million (ppm) relative to tetramethylsilane in the ${ }^{1} \mathrm{H}$ and the dimethyl sulfoxide (DMSO) residual peak as a reference in the ${ }^{13} \mathrm{C}$ spectra (39.51 ppm). Coupling constants $(J)$ are reported in Hz. Mass spectra were collected on an HPLC-MS/MS instrument (HPLC, Agilent Technologies 1200 Series; MS, Agilent Technologies 6410 Triple Quad) using electrospray ionization in positive mode (Agilent Technologies, USA). Elemental analyses were performed on a CHNS LECO analyzer (LECO Corporation, USA). All compounds were routinely checked by TLC with Merck silica gel 60F-254 glass plates using dichloromethane/methanol 9.5:0.5, 9:1, 8.5:1.5 and cyclohexane/ethyl acetate/methanol 1:1:0.5 as solvent systems. Spots were visualized by short-wave UV light and iodine vapor. Column chromatography was performed on silica gel $0.063-0.200 \mathrm{~mm}$. 
All chemicals and solvents were of analytical grade and were purchased from commercial sources. 4-Chloro-2,8-bis(trifluoromethyl)quinoline, butane-1,4-diamine, (E)-4-ethoxy-4-oxobut-2-enoic acid (mono-ethyl fumarate), 3-fluoroaniline, 4-fluoroaniline, 3-chloroaniline, 4-chloroaniline, 3-trifluoromethylaniline, 4-trifluoromethylaniline and triethylamine (TEA) were purchased from Merck $\mathrm{GmbH}$ (Germany), and (1-[bis(dimethylamino) methylene]-1H-1,2,3-triazolo[4,5-b]pyridinium 3-oxid hexafluorophosphate (HATU) and $\mathrm{N}, \mathrm{N}$-diisopropylethylamine (DIEA) were purchased from Alfa Aesar (USA). Anhydrous solvents were dried and redistilled prior to use.

\section{Syntheses}

(E)-ethyl 4-chloro-4-oxobut-2-enoate (Mono-ethyl fumarate chloride) (1). - A solution of $0.288 \mathrm{~g}$ mono-ethyl fumarate $(2 \mathrm{mmol})$ in $7 \mathrm{~mL}$ thionyl chloride was kept overnight and evaporated under reduced pressure. The residue was triturated several times with anhydrous dichloromethane and the solvent was evaporated again. The crude product $(0.315 \mathrm{~g}$, $97 \%$ ) was used in further reaction without purification.

$\mathrm{N}^{1}$-[2,8-bis(trifluoromethyl)quinolin-4-yl]butane-1,4-diamine (2). - A mixture of $0.599 \mathrm{~g}$ (0.02 mol) 4-chloro-2,8-bis(trifluoromethyl)quinoline and $1.763 \mathrm{~g}$ 1,4-diaminobutane $(0.02$ mol) was stirred under microwave irradiation $(300 \mathrm{~W})$ at $95^{\circ} \mathrm{C}$. After $0.5 \mathrm{~h}$, the reaction mixture was diluted with dichloromethane, extracted with $5 \% \mathrm{NaOH}(4 \times 40 \mathrm{~mL})$ and washed with water $(2 \times 40 \mathrm{~mL})$. The organic layer was dried over anhydrous sodium sulfate, filtrated and evaporated under reduced pressure. White solid 2 was obtained $(0.632 \mathrm{~g}$, $90 \%$ ) and used in further reaction without purification.

Ethyl (E)-4-[(4-\{[2,8-bis(trifluoromethyl)quinolin-4-yl]amino\}butyl)amino]-4-oxobut-2-enoate (3). - A solution of $0.527 \mathrm{~g}(1.5 \mathrm{mmol})$ of amine 2 and $0.152 \mathrm{~g}(1.5 \mathrm{mmol})$ TEA in $10 \mathrm{~mL}$ of anhydrous dichloromethane was added dropwise to chloride 1 dissolved in $10 \mathrm{~mL}$ anhydrous dichloromethane. The reaction mixture was stirred for $1 \mathrm{~h}$ at room temperature and extracted 3 times with brine. The organic layer was dried over sodium sulfate, filtered and evaporated under reduced pressure. After purification by column chromatography (mobile phase dichloromethane/methanol 9.5:0.5) and crystallization from ether, $0.473 \mathrm{~g}(66 \%)$ of pale yellow solid 3 was obtained.

(E)-4-[(4-\{[2,8-bis(trifluoromethyl)quinolin-4-yl]amino\}butyl)amino]-4-oxobut-2-enoic acid (4). - A solution of $0.126 \mathrm{~g}$ ( $3 \mathrm{mmol})$ lithium hydroxide monohydrate in $10 \mathrm{~mL}$ water was added to a solution of $0.286 \mathrm{~g}(0.6 \mathrm{mmol})$ ester 3 in $10 \mathrm{~mL}$ methanol. The reaction mixture was stirred for $3 \mathrm{~h}$ at room temperature. Methanol was evaporated under reduced pressure and the aqueous residue was acidified with $10 \%-\mathrm{HCl}$ to $\mathrm{pH} 1$. The precipitated product was filtered and washed with water until neutral $\mathrm{pH}$ was reached. $0.261 \mathrm{~g}$ (97\%) of white solid 4 was obtained.

Fumardiamides 5-10: General procedure. - A solution of $0.121 \mathrm{~g}(0.27 \mathrm{mmol})$ of compound 4, $0.068 \mathrm{~g}(0.54 \mathrm{mmol})$ DIEA and $0.103 \mathrm{~g}(0.27 \mathrm{mmol})$ HATU in $1 \mathrm{~mL}$ of $N, N$-dimethylformamide was stirred at room temperature. After $10 \mathrm{~min}, 0.297 \mathrm{mmol}$ of the corresponding halogenaniline was added. The reaction mixture was stirred 2-24 h at room temperature, evaporated under reduced pressure, dissolved in $8 \mathrm{~mL}$ ethyl acetate and extracted 3 times with water. The organic layer was dried over sodium sulfate, filtered and evaporated un- 
der reduced pressure. The crude products were purified by column chromatography (mobile phase dichloromethane/methanol 9.5:0.5) and crystallized from ether or petroleum ether.

(2E)-N'-(4-\{[2,8-bis(trifluoromethyl)quinolin-4-yl]amino\}butyl)-N-(3-fluorophenyl)but-2-enediamide (5). - Reaction of $0.121 \mathrm{~g}$ acid 4 and $0.033 \mathrm{~g}$ (0.297 $\mathrm{mmol})$ 3-fluoroaniline; after purification, $0.063 \mathrm{~g}(43 \%)$ of white solid 5 was obtained.

(2E)-N'-(4-\{[2,8-bis(trifluoromethyl)quinolin-4-yl]amino\}butyl)-N-(4-fluorophenyl)but-2-enediamide (6). - Reaction of $0.121 \mathrm{~g}$ acid 4 and $0.033 \mathrm{~g}$ (0.297 $\mathrm{mmol}) 4$-fluoroaniline; after purification, $0.056 \mathrm{~g}$ ( $38 \%$ ) of white solid 6 was obtained.

(2E)-N'-(4-\{[2,8-bis(trifluoromethyl)quinolin-4-yl]amino\}butyl)-N-(3-chlorophenyl)but-2-enediamide (7). - Reaction of $0.121 \mathrm{~g}$ acid 4 and $0.038 \mathrm{~g}$ (0.297 mmol) 3-chloroaniline; after purification, $0.072 \mathrm{~g}(48 \%)$ of white solid 7 was obtained.

(2E)-N'-(4-\{[2,8-bis(trifluoromethyl)quinolin-4-yl]amino\}butyl)-N-(4-chlorophenyl)but-2-enediamide (8). - Reaction of $0.121 \mathrm{~g}$ acid 4 and $0.038 \mathrm{~g}(0.297 \mathrm{mmol})$ 4-chloroaniline; after purification, $0.045 \mathrm{~g}(31 \%)$ of white solid 8 was obtained.

(2E)-N'-(4-\{[2,8-bis(trifluoromethyl)quinolin-4-yl]amino\}butyl)-N-[3-(trifluoromethyl)phenyl]but-2-enediamide (9). - Reaction of $0.121 \mathrm{~g}$ acid 4 and $0.048 \mathrm{~g}$ (0.297 mmol) 3-trifluoromethylaniline; after purification, $0.056 \mathrm{~g}$ (35\%) of white solid 9 was obtained.

(2E)-N'-(4-\{[2,8-bis(trifluoromethyl)quinolin-4-yl]amino\}butyl)-N-[4-(trifluoromethyl)phenyl]but-2-enediamide (10). - Reaction of $0.121 \mathrm{~g}$ acid 4 and $0.048 \mathrm{~g}$ (0.297 $\mathrm{mmol})$ 4-trifluoromethylaniline; after purification, $0.037 \mathrm{~g}(23 \%)$ of white solid 10 was obtained.

\section{Biological evaluation}

In vitro activity against P. berghei hepatic stages. - Activity of the synthesized compounds against $P$. berghei infection in a human hepatoma cell line was assessed employing a luminescence-based method, as previously described (25). Briefly, hepatic infection was determined by measuring the luminescence intensity of lysates of Huh7 cells, a human hepatoma cell line, infected with firefly luciferase-expressing $\mathrm{P}$. berghei sporozoites $(\mathrm{Pb}$ Luc). Huh7 cells $\left(1.0 \times 10^{4}\right.$ per well) were seeded in 96-well plates on the day before infection. One hour prior to infection, the medium was replaced by medium containing the appropriate drug concentration. Addition of $1.0 \times 10^{4} \mathrm{~Pb}$-Luc sporozoites was followed by centrifugation at $1800 \times g$ for $5 \mathrm{~min}$ and the parasite infection load was measured $48 \mathrm{~h}$ after parasite addition with a bioluminescence assay (Biotium, USA) using a multi-plate reader Infinite M200 (Tecan, Switzerland). The effect of different treatments on the viability of HuH7 cells was assessed using the CellTiter-Blue assay (Promega, USA) according to the manufacturer's protocol. Nonlinear regression analysis was employed to fit the normalized results of the dose-response curves, and $I C_{50}$ values were determined using GraphPad Prism V 5.0.

In vitro drug sensitivity against P. falciparum erythrocytic stages. - In vitro activity of tested compounds was evaluated against asexual erythrocytic stages of two $P$. falciparum 
laboratory strains, 3D7 (chloroquine sensitive) and Dd2 (chloroquine resistant). Antiplasmodial activity of fumardiamides $\mathbf{5 - 1 0}$ was assessed by histidine-rich protein 2 (HRP2) ELISA, as described before $(26,27)$. As controls, mefloquine hydrochloride (Sigma, USA) and chloroquine diphosphate (Sigma) were used. In brief, 96-well plates were pre-coated with the respective compounds or control drugs at a threefold dilution before highly synchronized ring stage parasites were added into complete culture medium at a hematocrit of $1.5 \%$ and parasitaemia of $0.05 \%$. After three days of incubation at $37{ }^{\circ} \mathrm{C}, 5 \% \mathrm{CO}_{2}$ and $5 \%$ oxygen, plates were freeze thawed three times until analyzed by HRP2-ELISA. All compounds were evaluated in duplicate in at least two independent experiments. The $50 \%$ inhibitory concentration $\left(I C_{50}\right)$ was determined by analyzing the nonlinear regression of log concentration-response curves using the drc-package v0.9.0 of R v3.2.2. (28).

Cytotoxicity assay. - Cytotoxicity of novel compounds against the human liver cancer cell line Hep G2 (Leibniz Institute DSMZ - German Collection of Microorganisms and Cell Cultures, Germany) was evaluated using the neutral red assay (29). In brief, human cells were seeded to a 96-well plate in culture medium; on the following day, a serial dilution of the respective compound was added. After one day incubation, cytotoxicity was assessed by addition of Neutral Red and subsequent lysis of cells and measuring absorbance at $\lambda=570 \mathrm{~nm}$ in a plate reader. Inhibitory concentrations were calculated.

\section{RESULTS AND DISCUSSION}

Novel fumaric acid diamides 5-10, bearing 2,8-bis(trifluoromethyl)quinoline and 3- or 4-substituted fluoro-, chloro- or trifluoromethylaniline moieties, were prepared by the simple reaction procedures summarized in Scheme 1. The first precursor, $(E)$-ethyl 4-chloro-4-oxobut-2-enoate) (1), was prepared from mono-ethyl fumarate and thionyl chloride, while the second, $N^{1}$-(2,8-bis(trifluoromethyl)quinolin-4-yl)butane-1,4-diamine (2), was prepared from 4-chloro-2,8-bis(trifluoromethyl)quinoline and 1,4-diaminobutane under microwave irradiation. Compounds 1 and 2 reacted under mild reaction conditions to give product 3. In this reaction step, TEA was used as a hydrochloride acceptor. Basic hydrolysis

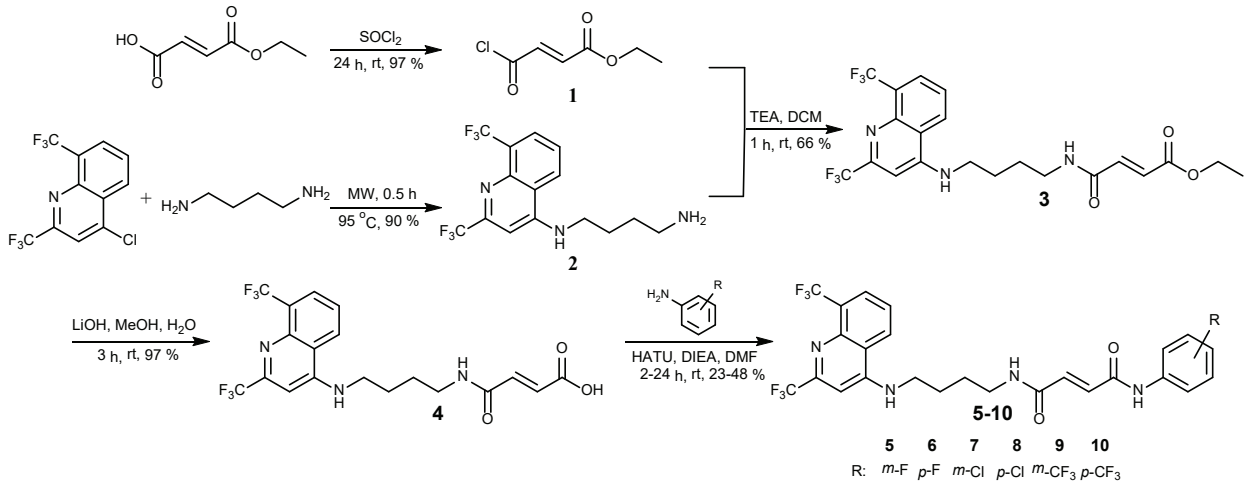

Scheme 1 
of 3 afforded the corresponding acid 4, which reacted with selected halogenanilines and formed the title fumardiamides $\mathbf{5 - 1 0}$. HATU was used as a coupling reagent and DIEA as a base (known as Hünig's base). The common precursor 4 enables relatively easy preparation of diverse target compounds.

Purification of compounds was carried out using crystallization methods and/or column chromatography. Yields for the first two reaction steps were high, but rather low for the last one, $23-48 \%$.

Structures of the new compounds were confirmed by ${ }^{1} \mathrm{H},{ }^{13} \mathrm{C}$ NMR and IR spectra and additionally by elemental analysis. Chemical shifts, multiplicities and coupling constants confirmed the proposed structures. Analytical and spectral data of the target compounds 5-10 and their precursors are given in Table I. Atom numbering used in the current study is indicated in Fig. 1.<smiles>[R]c1ccc(NC(=O)/C=C/C(=O)NCCCCNc2cc(C(F)(F)F)nc3c(C(F)(F)F)cccc23)cc1</smiles>

Fig. 1. Atom numbering of compounds 5-10.

In ${ }^{1} \mathrm{H}$ NMR spectra, NH-1' signals were visible as sharp singlets between $\delta 10.78$ and 10.45 , NH-5 signals as triplets at $8.55-8.47$ ppm, while NH-10 signals were mixed with aromatic $\mathrm{H}$-atoms. All $\mathrm{NH}$ signals were $\mathrm{D}_{2} \mathrm{O}$ exchangeable. $\mathrm{In}^{13} \mathrm{C}$ NMR spectra, the $\mathrm{CF}_{3}$ group at position 21 had a signal between $\delta 129.41$ and $116.72 \mathrm{ppm}$ and between 127.11 and 116.23 ppm at position $\mathrm{C}-20$. Two additional $\mathrm{CF}_{3}$ groups in compounds $\mathbf{9}$ and $\mathbf{1 0}$ appeared at

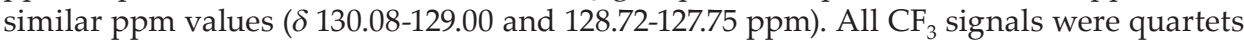
with high coupling constants $(277.70-272.73 \mathrm{~Hz})$. The carbon atoms bearing trifluoromethyl groups, i.e., atoms C-15, C-13 and C-4' or C-5', in compounds $\mathbf{9}$ and $\mathbf{1 0}$ showed quartets with markedly lower coupling constants $(33.22-27.30 \mathrm{~Hz})$, while fluorosubstituted carbons $4^{\prime}$ and $5^{\prime}$ in compounds 5 and 6 appeared as doublets at $\delta 163.71-160.51$ and 159.03-157.44 ppm. Signals of the analogous chlorosubstituted carbons in compounds 7 and 8 were downshifted at $\delta 133.12$ and 127.38 ppm. In all compounds, carbonyl C-atoms C-1 and C-4 appeared between $\delta 163.41$ and $162.16 \mathrm{ppm}$. IR spectra revealed the presence of two sets of amide I and amide II signals between 1652 and $1512 \mathrm{~cm}^{-1}$.

Chemical structure of the new compounds was also supported by mass spectrometry analysis. Molecular ion peaks corresponding to the expected molecular masses were obtained for all compounds. $\mathrm{m} / \mathrm{z}$ data and the expected relative molecular masses are given in Table I, while all IR, NMR and mass spectra are available as Supplementary material.

We have also applied Chemicalize.org (30) and SwissADME programs (31) to compute physicochemical descriptors as well as to predict ADME parameters, pharmacokinetic properties, drug-like nature and medicinal chemistry friendliness of our fumardiamides. A set of physicochemical parameters, i.e., number of atoms, molecular mass (MW), partition coefficient $(\log P)$, number of $\mathrm{H}$-bond donors (HBD), number of H-bond acceptors (HBA), molar refractivity (MR) and topological polar surface area (TPSA) are given in Table 


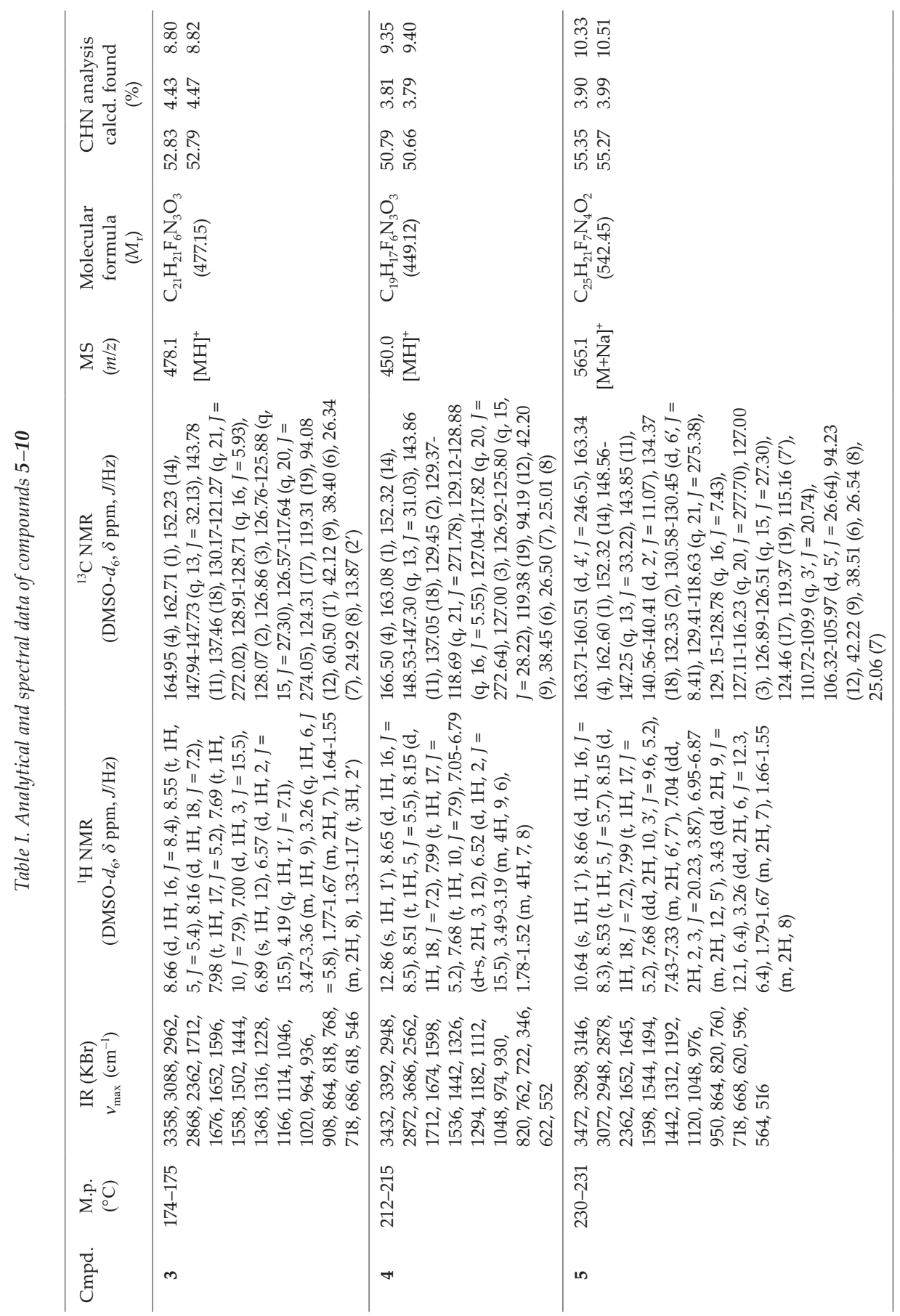




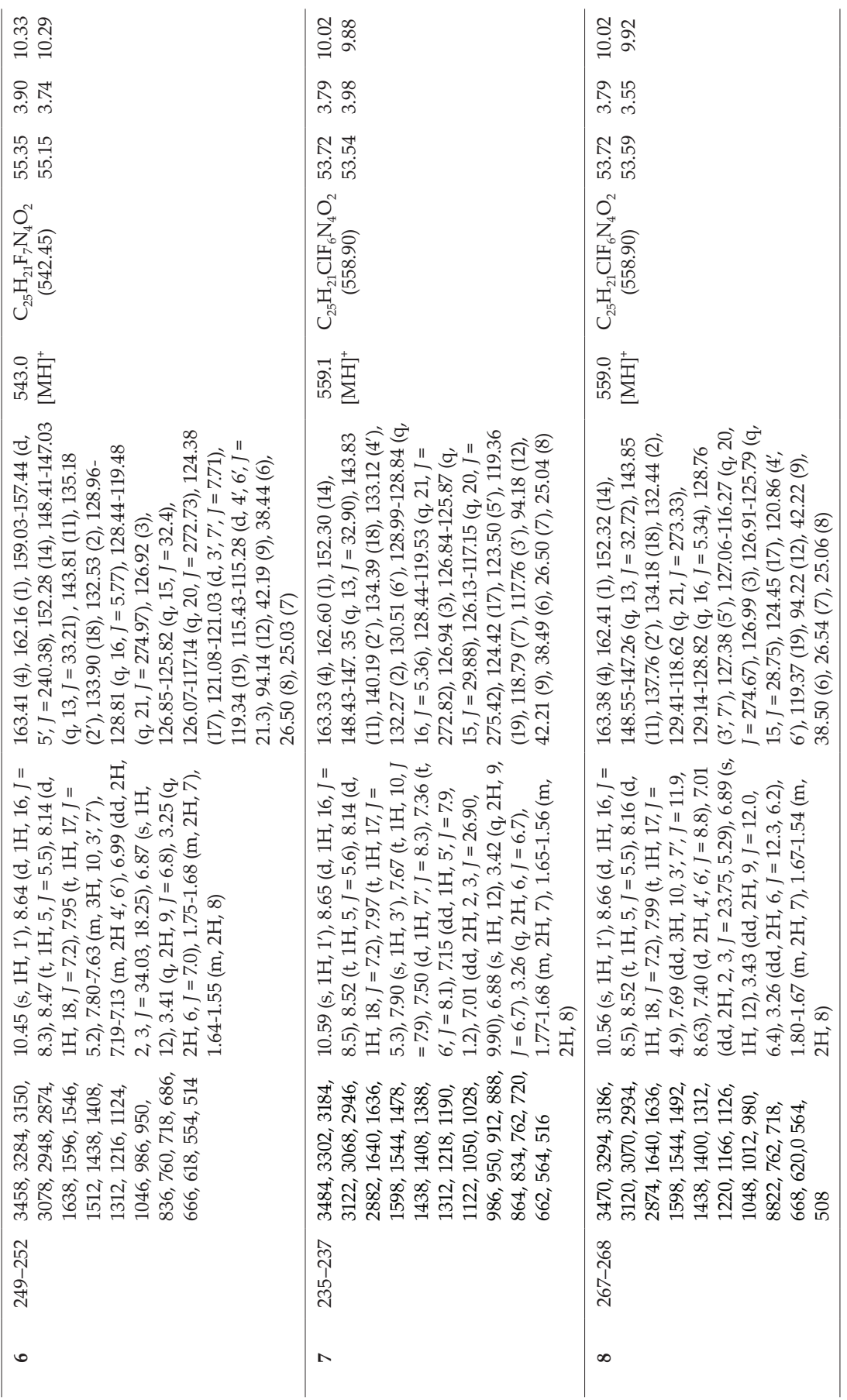




\begin{tabular}{|c|c|}
\hline ơ & 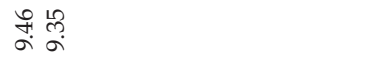 \\
\hline$\vec{\infty}$ & $\begin{array}{l}\hat{n} \\
\hat{n} \\
\infty \\
\infty\end{array}$ \\
\hline it & 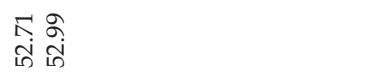 \\
\hline 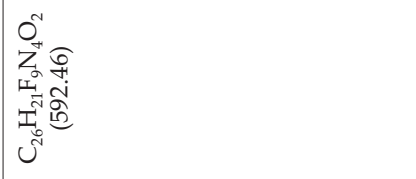 & 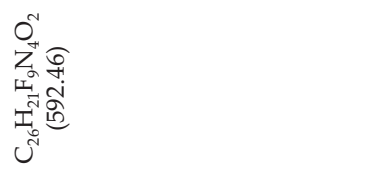 \\
\hline 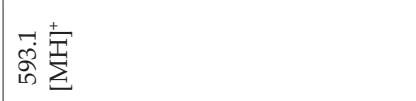 & 总苞 \\
\hline 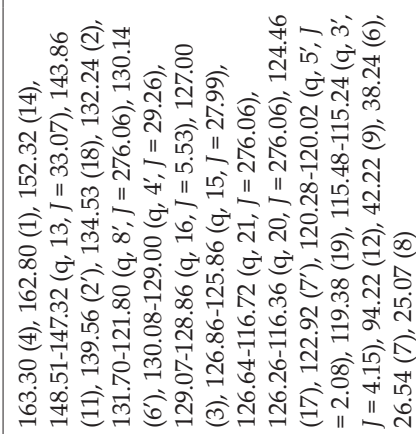 & 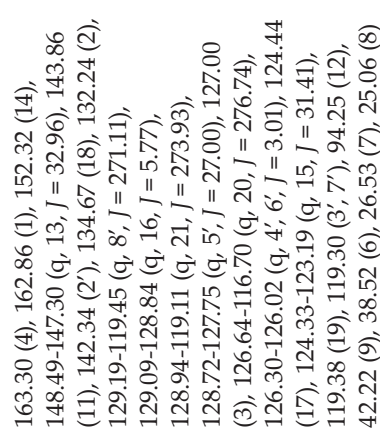 \\
\hline 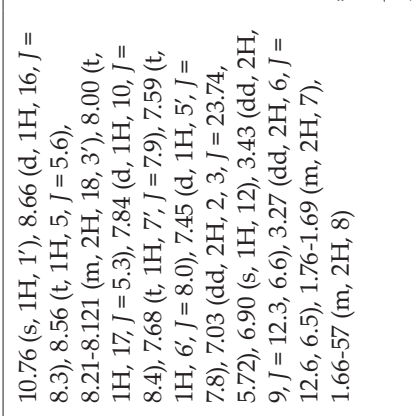 & 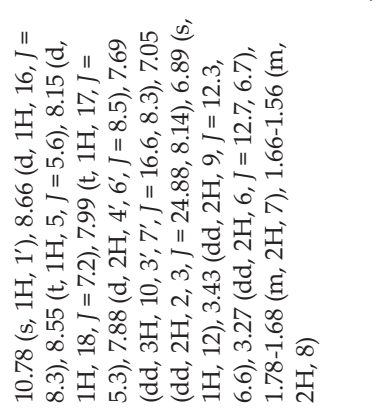 \\
\hline 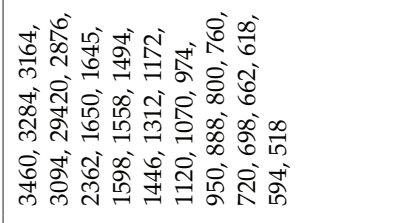 & 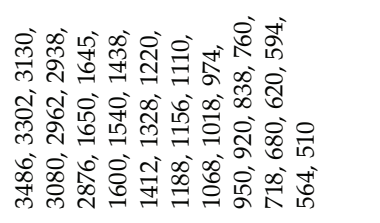 \\
\hline$\stackrel{\mathscr{N}}{\approx}$ & $\begin{array}{l}\stackrel{0}{0} \\
\text { N } \\
\text { ลิ }\end{array}$ \\
\hline & 욱 \\
\hline
\end{tabular}


Table II. Calculated physiochemical descriptors of diamides 5-10 (30)

\begin{tabular}{ccccccccc}
\hline Cmpd. & $\begin{array}{c}\text { Molecular } \\
\text { formula }\end{array}$ & $\begin{array}{c}\text { Number } \\
\text { of atoms }\end{array}$ & $M_{\mathrm{r}}$ & $\log P$ & $\mathrm{HBD}$ & $\mathrm{HBA}$ & $\begin{array}{c}\mathrm{MR} \\
\left(\mathrm{cm}^{3} \mathrm{~mol}^{-1}\right)\end{array}$ & $\begin{array}{c}\text { TPSA } \\
\left(\AA^{2}\right)\end{array}$ \\
\hline $\mathbf{5}$ & $\mathrm{C}_{25} \mathrm{H}_{21} \mathrm{~F}_{7} \mathrm{~N}_{4} \mathrm{O}_{2}$ & 59 & 542.458 & 5.10 & 3 & 4 & 129.11 & 83.12 \\
$\mathbf{6}$ & $\mathrm{C}_{25} \mathrm{H}_{21} \mathrm{~F}_{7} \mathrm{~N}_{4} \mathrm{O}_{2}$ & 59 & 542.458 & 5.10 & 3 & 4 & 129.11 & 83.12 \\
$\mathbf{7}$ & $\mathrm{C}_{25} \mathrm{H}_{21} \mathrm{ClF}_{6} \mathrm{~N}_{4} \mathrm{O}_{2}$ & 59 & 558.910 & 5.57 & 3 & 4 & 133.70 & 83.12 \\
$\mathbf{8}$ & $\mathrm{C}_{25} \mathrm{H}_{21} \mathrm{ClF}_{6} \mathrm{~N}_{4} \mathrm{O}_{2}$ & 59 & 558.910 & 5.57 & 3 & 4 & 133.70 & 83.12 \\
$\mathbf{9}$ & $\mathrm{C}_{26} \mathrm{H}_{21} \mathrm{~F}_{9} \mathrm{~N}_{4} \mathrm{O}_{2}$ & 62 & 592.466 & 5.84 & 3 & 4 & 134.87 & 83.12 \\
$\mathbf{1 0}$ & $\mathrm{C}_{26} \mathrm{H}_{21} \mathrm{~F}_{9} \mathrm{~N}_{4} \mathrm{O}_{2}$ & 62 & 592.466 & 5.84 & 3 & 4 & 134.87 & 83.12 \\
\hline
\end{tabular}

$M_{\mathrm{r}}$ - relative molecular mass; $\log P$ - partition coefficient; HBD - H-bond donor; HBA - H-bond acceptor; MR molecular refractivity; TPSA - topological polar surface area

II (30). All compounds showed minimum aberration in molecular masses and $\log P$, while the other four parameters are fully in agreement with Lipinski's and Gelovani's rules. SwissADME bioavailability radars for the most active compounds 5, 7 and $\mathbf{9}$ are given in Fig. 2 (31). Radars enable a first glance at the drug-likeness of the molecules. The pink area represents the optimal range for each property: lipophilicity (LIPO) (XLOGP3 between -0.7 and +5.0 ), molecular mass (SIZE) (between 150 and $500 \mathrm{~g} \mathrm{~mol}^{-1}$ ), polarity (POLAR) (TPSA between 20 and $130 \AA^{2}$ ), solubility (INSOLU) (log $S$ not higher than 6), saturation (INSATU) (fraction of carbons in the $\mathrm{sp}^{3}$ hybridization not less than 0.25 ), and flexibility (FLEX) (no more than 9 rotatable bonds). All three compounds are too flexible and are thus predicted as not orally bioavailable.

\section{Biological evaluation}

To evaluate the antiplasmodial potential of the title fumardiamides, in vitro assays against two strains of $P$. falciparum erythrocytic stages, $P f 3 \mathrm{D} 7$ and $P f \mathrm{Dd} 2$, and against $P$. berghei hepatic stages were performed. Our results showed that only compound 5 displayed marked activity against $P$. falciparum blood stages, with an $I C_{50}$ of $2.9 \mu \mathrm{mol} \mathrm{L}-1$ (Table III). On the other hand, all the compounds evaluated in this work showed promising antiplasmodial in vitro activity against $P$. berghei. Fumardiamides were tested at 1 and 10 $\mu \mathrm{mol} \mathrm{L}-1$, and DMSO was used as a negative control (Fig. 3). The most active compounds (5, 7 and 9) had very similar $I C_{50}$ values, ranging between 3.04 and $4.16 \mu \mathrm{mol} \mathrm{L}^{-1}$ (Fig. 4), indicating that the type of halogen (fluorine or chlorine) had no influence on the compound activity against the parasite's hepatic stages, but had a slight impact on cytotoxicity. Among the three most active compounds, 3-fluoro derivative 5 showed the best activity/ toxicity ratio (Table IV). Replacement of the halogen atom with $\mathrm{CF}_{3}$ group caused slight perturbations of electron density of the aromatic scaffold, but this change also had a negligible effect on the activity. Comparison of the structural isomers 5 and 6, 7 and 8, and 9 and 10 revealed that meta-substituted derivatives were slightly more active than the analogous para-substituted derivatives. Cytotoxicity studies performed on the human liver cancer cell line (HepG2) cells revealed low cytotoxicity of fumardiamides 5-10. These studies 

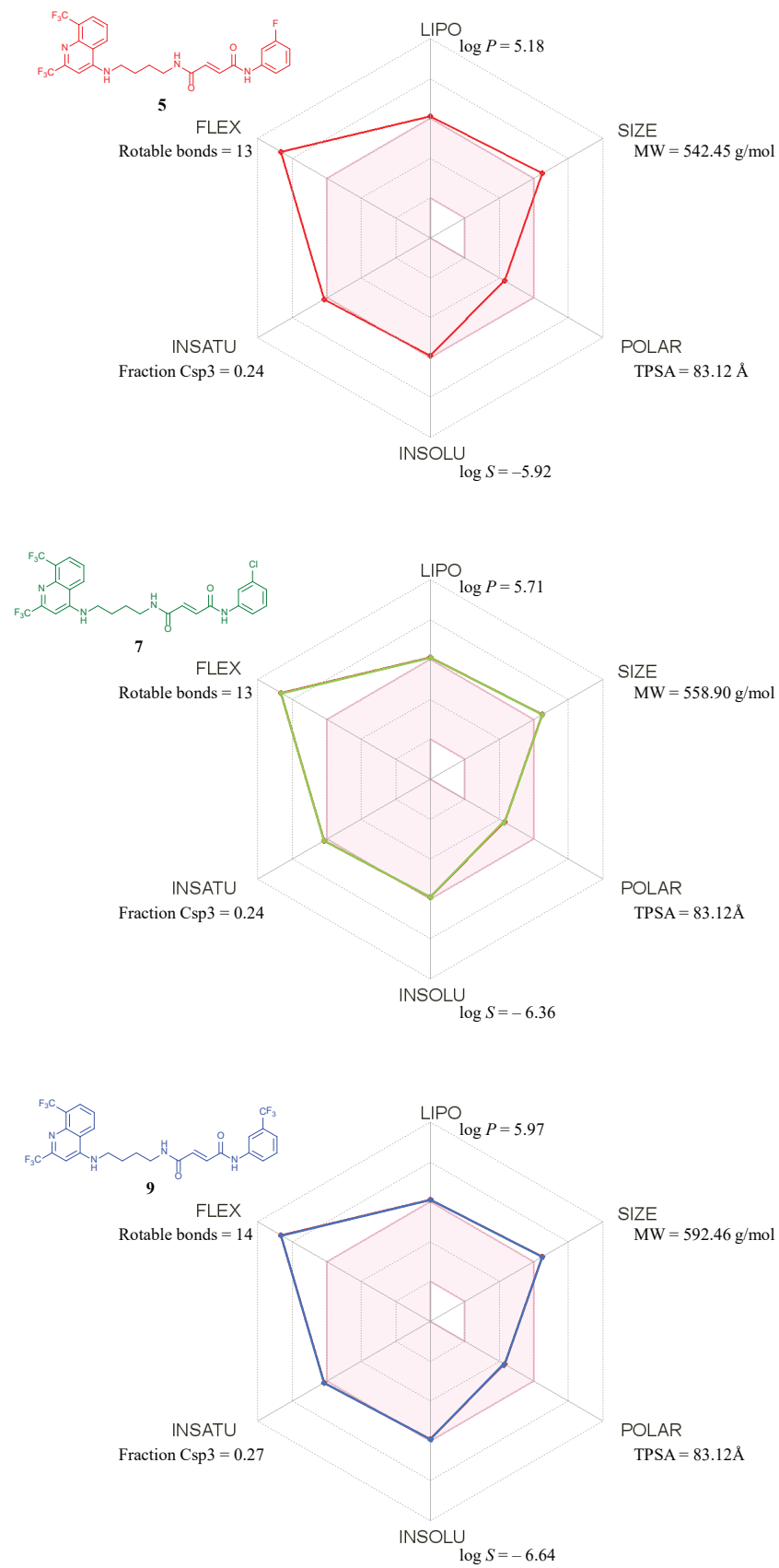

Fig. 2. Bioavailability radars for the most active compounds 5, 7 and 9 . The pink area represents the optimal range for each property (lipophilicity, size, polarity, solubility, saturation and flexibility). 


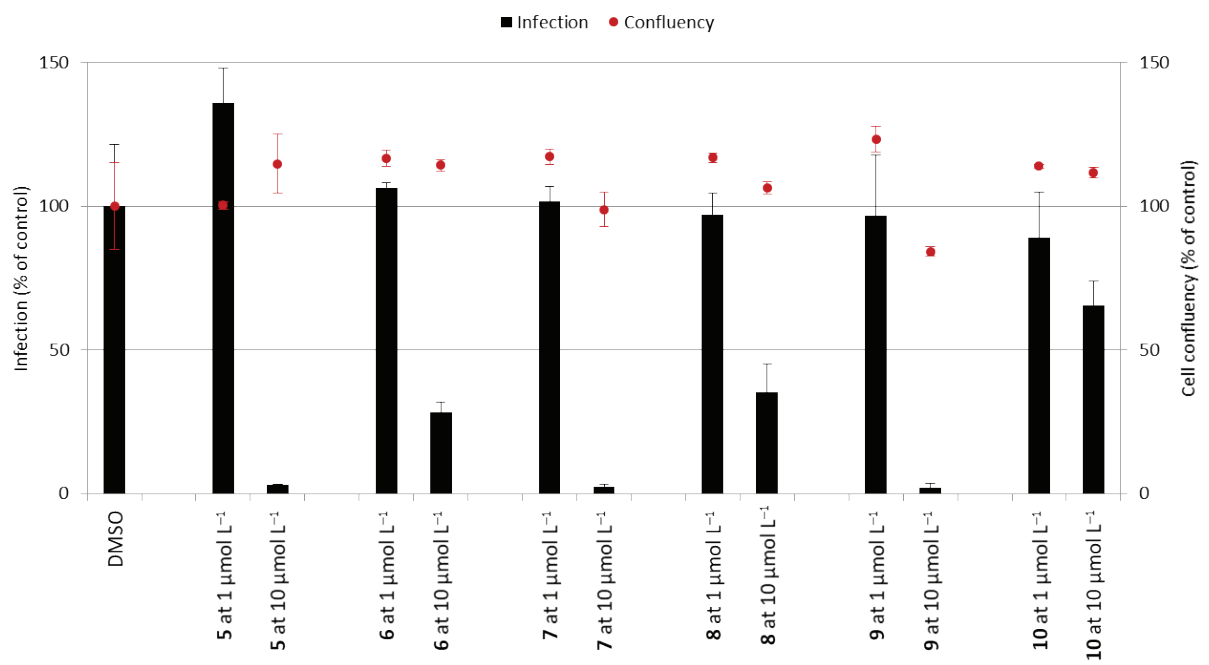

Fig. 3. Activity of compounds $\mathbf{5 - 1 0}$ against $P$. berghei liver-stages at 1 and $10 \mu \mathrm{mol} \mathrm{L}^{-1}$ concentrations. Anti-infective activity (infection scale, bars) is shown. Results represent mean $\pm \mathrm{SD}, n=1$.

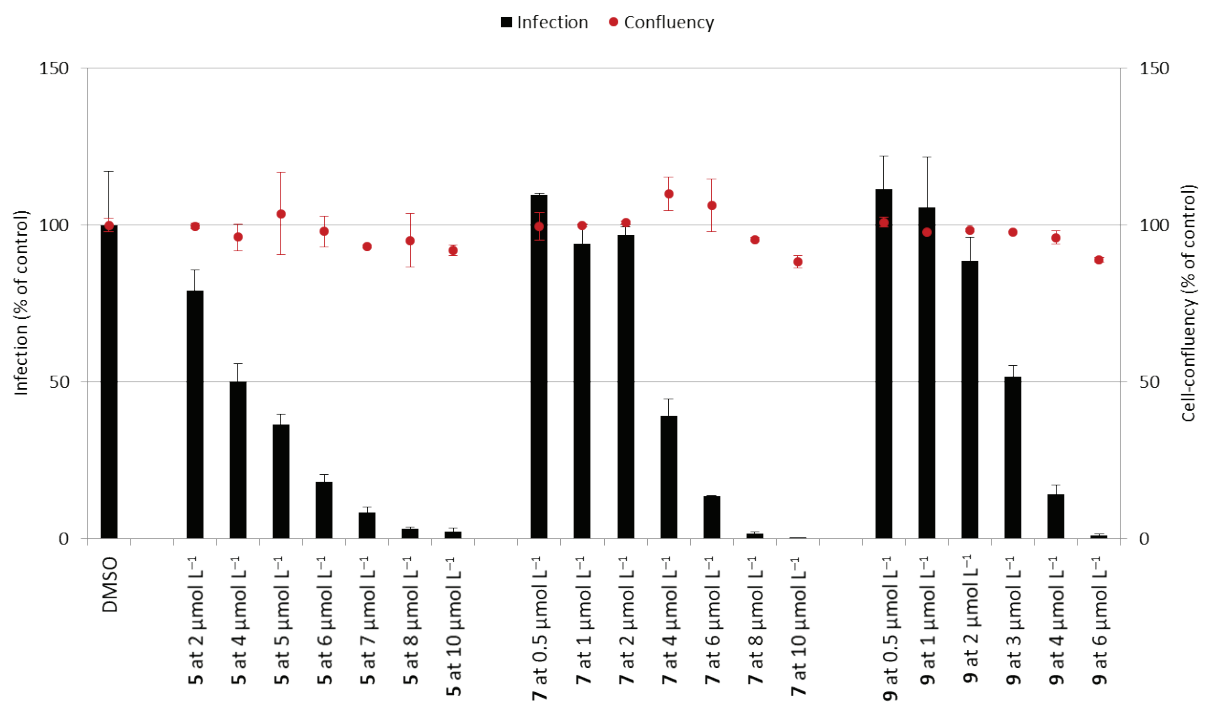

Fig. 4. $I C_{50}$ of selected MQ-derivatives against P. berghei hepatic stages. $I C_{50}=4.16(5), 3.64(7)$ and 3.04 (9) $\mu \mathrm{mol} \mathrm{L}^{-1}$. Results represent mean $\pm \mathrm{SD}, n=1$.

are only preliminary. To get a better insight into the toxicity of prepared compounds, more cell lines should be tested and additional cytotoxicity tests should be performed. 
Table III. IC ${ }_{50}$ values of compounds $\mathbf{5 - 1 0}$ against the erythrocytic stage of two P. falciparum strains

Chloroquine

Table IV. Cytotoxicity screening of compounds 5-10 towards the human liver cancer cell line (Hep G2)

\begin{tabular}{cc}
\hline Cmpd. & $\begin{array}{c}I_{50} \\
\left(\mu \mathrm{mol} \mathrm{L}^{-1}\right)\end{array}$ \\
\hline $\mathbf{5}$ & $64.1 \pm 54.2$ \\
$\mathbf{6}$ & $>100$ \\
$\mathbf{7}$ & $10.0 \pm 3.6$ \\
$\mathbf{8}$ & $>100$ \\
$\mathbf{9}$ & $13.0 \pm 2.6$ \\
$\mathbf{1 0}$ & $>100$ \\
Primaquine & $148.0 \pm 3.5$ \\
\hline
\end{tabular}




\section{CONCLUSIONS}

Novel fumardiamides 5-10 with the mefloquine pharmacophore and Michael acceptor motif were designed and synthesized through multi-step reactions. Three compounds, namely (2E)- $N^{\prime}-(4-\{[2,8$-bis(trifluoromethyl)quinolin-4-yl]amino\}butyl)- $N$-(3-fluorophenyl) but-2-enediamide (5), (2E)- $N^{\prime}$-(4-\{[2,8-bis(trifluoromethyl)quinolin-4-yl]amino\}butyl)- $N$-(3chlorophenyl)but-2-enediamide (7) and (2E)- $N^{\prime}-(4-\{[2,8$-bis(trifluoromethyl)quinolin-4-yl] amino\}butyl)- $\mathrm{N}$-[3-(trifluoromethyl)phenyl]but-2-enediamide (9), provided fairly promising results in the in vitro bioassay against $P$. berghei liver stages, while compound 5 was also active against the blood stages of two $P$. falciparum strains. These compounds could serve as starting points for further optimization and development of more potent agents.

Acknowledgments. - The study was supported by the Croatian Science Foundation (research project IP-2014-09-1501) and University of Zagreb (support for 2018). The work of doctoral student Maja Beus was fully supported by the Young researchers' career development project - training of doctoral students of the Croatian Science Foundation, funded by the European Union Social Fund.

Supplementary material is available upon request.

Abbreviations, acronyms, symbols. - CQ - chloroquine; DIEA - N,N-diisopropylethylamine; HATU - 1-[bis(dimethylamino)methylene]-1H-1,2,3-triazolo[4,5-b]pyridinium 3-oxid hexafluorophosphate; HBA - H-bond acceptor; HBD - H-bond donor; Hep G2 - human liver cancer cell line; MQ - mefloquine; PQ - primaquine; TEA - trimethylamine; TPSA - topological polar surface area.

\section{REFERENCES}

1. G. Padmanaban and P. N. Rangarajan, Heme metabolism of Plasmodium is a major antimalarial target, Biochem. Biophys. Res. Commun. 268 (2000) 665-668; https://doi.org/10.1006/bbrc.1999.1892

2. C. Even, S. Friedman and K. Lamouar, Bipolar disorder after mefloquine treatment, J. Psychiatry Neurosci. 26 (2001) 252-253.

3. F. de Pilla Varotti, A. C. C. Botelho, A. A. Andrade, R. C. de Paula, E. M. S. Fagundes, A. Valverde, L. M. U. Mayer, J. S. Mendonça, M. V. N. de Souza, N. Boechat and A. U. Krettli, Synthesis, antimalarial activity, and intracellular targets of MEFAS, a new hybrid compound derived from mefloquine and artesunate, Antimicrob. Agents Chemother. 52 (2008) 3868-3874; https://doi.org/10.1128/ AAC.00510-08

4. A. R. Hamann, C. de Kock, P. J. Smith, W. A. L. van Otterlo and M. A. L. Blackie, Synthesis of novel triazole-linked mefloquine derivatives: Biological evaluation against Plasmodium falciparum, Bioorg. Med. Chem. Lett. 24 (2014) 5466-5469; https://doi.org/10.1016/j.bmcl.2014.10.015

5. N. Sharma, S. Thomas, E. B. Golden, F. M. Hofman, T. C. Chen, N. A. Petasis, A. H. Schönthal and S. G. Louie, Inhibition of autophagy and induction of breast cancer cell death by mefloquine, an antimalarial agent, Cancer Lett. 326 (2012) 143-154; https://doi.org/10.1016/j.canlet.2012.07.029

6. F. A. Rodrigues, I. S. Bomfim, B. C. Cavalcanti, C. Pessoa, R. S. Goncalves, J. L. Wardell, S. M. Wardell and M. V. de Souza, Mefloquine-oxazolidine derivatives: A new class of anticancer agents, Chem. Biol. Drug Des. 83 (2014) 126-131; https://doi.org/10.1111/cbdd.12210

7. T. Küster, B. Stadelmann, R. Rufener, C. Risch, J. Müller and A. Hemphill, Oral treatments of Echinococcus multilocularis-infected mice with the antimalarial drug mefloquine that potentially interacts with parasite ferritin and cystatin, Int. J. Antimicrob. Agents 46 (2015) 546-551; https://doi. org/10.1016/j.ijantimicag.2015.07.016

8. L. E. Bermudez, P. Kolonoski, L. E. Seitz, M. Petrofsky, R. Reynolds, M. Wu and L. S. Young, SRI286, a thiosemicarbazole, in combination with mefloquine and moxifloxacin for treatment of mu- 
rine Mycobacterium avium complex disease, Antimicrob. Agents Chemother. 48 (2004) 3556-3558; https://doi.org/10.1128/AAC.48.9.3556-3558.2004

9. L. Danelishvili, M. Wu, L. S. Young and L. E. Bermudez, Genomic approach to identifying the putative target of and mechanisms of resistance to mefloquine in Mycobacteria, Antimicrob. Agents Chemother. 49 (2005) 3707-3714; https://doi.org/10.1128/AAC.49.9.3707-3714.2005

10. R. S. Gonçalves, C. R. Kaiser, M. C. Lourenço, F. A. Bezerra, M. V. de Souza, J. L. Wardell, S. M. Wardell, M. D. Henriques and T. Costa, Mefloquine-oxazolidine derivatives, derived from mefloquine and arenecarbaldehydes: In vitro activity including against the multidrug-resistant tuberculosis strain T113, Bioorg. Med. Chem. 20 (2012) 243-248; https://doi.org/10.1016/j.bmc.2011.11.006

11. J. Mao, H. Yuan, Y. Wang, B. Wan, D. Pak, R. He and S. G. Franzblau, Synthesis and antituberculosis activity of novel mefloquine-isoxazole carboxylic esters as prodrugs, Bioorg. Med. Chem. Lett. 20 (2010) 1263-1268; https://doi.org/10.1016/j.bmcl.2009.11.105

12. S. Eswaran, A. V. Adhikari, I. H. Chowdhury, N. K. Pal and K. D. Thomas, New quinoline derivatives: Synthesis and investigation of antibacterial and antituberculosis properties, Eur. J. Med. Chem. 45 (2010) 3374-3383; https://doi.org/10.1016/j.ejmech.2010.04.022

13. G. Džimbeg, B. Zorc, M. Kralj, K. Ester, K. Pavelić, J. Balzarini, E. De Clercq and M. Mintas, The novel primaquine derivatives of $\mathrm{N}$-alkyl, cycloalkyl or aryl urea: synthesis, cytostatic and antiviral activity evaluations, Eur. J. Med. Chem. 43 (2008) 1180-1187; https://doi.org/10.1016/j.ejmech.2007.09.001

14. M. Šimunović, I. Perković, B. Zorc, K. Ester, M. Kralj, D. Hadjipavlou-Litina and E. Pontiki, Urea and carbamate derivatives of primaquine: synthesis, cytostatic and antioxidant activities, Bioorg. Med. Chem. 17 (2009) 5605-5613; https://doi.org/10.1016/j.bmc.2009.06.030

15. I. Perković, S. Tršinar, J. Žanetić, M. Kralj, I. Martin-Kleiner, J. Balzarini, D. Hadjipavlou-Litina and A. M. Katsori, Novel 1-acyl-4-substituted semicarbazide derivatives of primaquine - synthesis, cytostatic, antiviral and antioxidative studies, J. Enzyme Inhib. Med. Chem. 28 (2013) 601-610; https://doi.org/10.3109/14756366.2012.663366

16. K. Pavić, I. Perković, M. Cindrić, M. Pranjić, I. Martin-Kleiner, M. Kralj, D. Schols, D. HadjipavlouLitina, A.-M. Katsori and B. Zorc, Novel semicarbazides and ureas of primaquine with bulky aryl or hydroxyalkyl substituents: Synthesis, cytostatic and antioxidative activity, Eur. J. Med. Chem. 86 (2014) 502-514; https://doi.org/10.1016/j.ejmech.2014.09.013

17. I. Perković, M. Antunović, I. Marijanović, K. Pavić, K. Ester, M. Kralj, J. Vlainić, I. Kosalec, D. Schols, D. Hadjipavlou-Litina, E. Pontiki and B. Zorc, Novel urea and bis-urea primaquine derivatives with hydroxyphenyl and halogenphenyl substituents: synthesis and biological evaluation, Eur. J. Med. Chem. 124 (2016) 622-636; https://doi.org/10.1016/j.ejmech.2016.08.021

18. K. Pavić, I. Perković, P. Gilja, F. Kozlina, K. Ester, M. Kralj, D. Schols, D. Hadjipavlou-Litina, E. Pontiki and B. Zorc, Design, synthesis and biological evaluation of novel primaquine-cinnamic acid conjugates of amide and acylsemicarbazide type, Molecules 21 (2016) 1629-1653; https://doi. org/10.3390/molecules21121629

19. K. Pavić, I. Perković, Š. Pospíšilová, M. Machado, D. Fontinha, M. Prudêncio, J. Jampilek, A. Coffey, L. Endersen, H. Rimac and B. Zorc, Primaquine hybrids as promising antimycobacterial and antimalarial agents, Eur. J. Med. Chem. 143 (2018) 769-779; https://doi.org/10.1016/j.ejmech.2017.11.083

20. J. Vlainić, I. Kosalec, K. Pavić, D. Hadjipavlou-Litina, E. Pontiki and B. Zorc, Insights into biological activity of ureidoamides with primaquine and amino acid moieties, J. Enzyme Inhib. Med. Chem. 33 (2018) 376-382; https://doi.org/10.1080/14756366.2017.1423067

21. J. Levatić, K. Pavić, I. Perković, L. Uzelac, K. Ester, M. Kralj, M. Kaiser, M. Rottmann, F. Supek and B. Zorc, Machine learning prioritizes synthesis of primaquine ureidoamides with high antimalarial activity and attenuated cytotoxicity, Eur. J. Med. Chem. 146 (2018) 651-667; https://doi. org/10.1016/j.ejmech.2018.01.062 
22. M. Beus, Z. Rajić, D. Maysinger, Z. Mlinarić, M. Antunović, I. Marijanović, D. Fontinha, M. Prudêncio, J. Held, S. Olgen and B. Zorc, SAHAquines, novel hybrids based on SAHA and primaquine motifs, as potential anticancer and antiplasmodial agents, ChemistryOpen 7 (2018) 624-638; https://doi.org/10.1002/open.201800117

23. Z. Rajić, M. Beus, H. Michnova, J. Vlainić, L. Persoons, I. Kosalec, J. Jampilek, D. Schols, T. Keser and B. Zorc, Asymmetric primaquine and halogenaniline fumardiamides as novel biologically active Michael acceptors, Molecules 23 (2018) Article ID 1724 (18 pages); https://doi.org/10.3390/ molecules23071724

24. I. Zhang, M. Beus, U. Stochaj, P. U. Le, B. Zorc, Z. Rajić, K. Petrecca and D. Maysinger, Inhibition of glioblastoma cell proliferation, invasion, and mechanism of action of a novel hydroxamic acid hybrid molecule, Cell Death Discov. 4 (2018) Article ID 41; https://doi.org/10.1038/s41420-018-0103-0

25. A. M. Mendes, I. S. Albuquerque, M. Machado, J. Pissarra, P. Meireles and M. Prudêncio, Inhibition of Plasmodium liver infection by ivermectin, Antimicrob. Agents Chemother. 61 (2017) e02005-16; https://doi.org/10.1128/AAC.02005-16

26. J. Held, T. Gebru, M. Kalesse, R. Jansen, K. Gerth, R. Müller and B. Mordmüller, Antimalarial activity of the myxobacterial macrolide chlorotonil A, Antimicrob. Agents Chemother. 58 (2014) 6378-6384; https://doi.org/10.1128/AAC.03326-14

27. H. Noedl, J. Bronnert, K. Yingyuen, B. Attlmayr, H. Kollaritsch and M. Fukuda, Simple histidinerich protein 2 double-site sandwich enzyme-linked immunosorbent assay for use in malaria drug sensitivity testing, Antimicrob. Agents Chemother. 49 (2005) 3575-3577; https://doi.org/10.1128/ AAC.49.8.3575-3577.2005

28. R Core Team, 2015, R: A language and environment for statistical computing. R Foundation for Statistical Computing, Vienna, Austria; https://www.R-project.org/; last access December 15, 2018

29. E. Borenfreund and J. A. Puerner, A simple quantitative procedure using monolayer cultures for cytotoxicity assays (HTD/NR-90), J. Tissue Culture Method 9 (1985) 7-9; https://doi.org/10.1007/ BF01666038

30. Chemicalize, 2017, ChemAxon Ltd., Budapest, Hungary; https://chemicalize.com; last access November 28, 2018

31. SwissADME Programs, Swiss Institute of Bioinformatics, Lausanne, Switzerland; http://www. swissadme.ch; last access November 28, 2018 